\title{
Under crossfire: thromboembolic risk in systemic lupus erythematosus
}

Giuseppe A. Ramirez ${ }^{1,2,3}$ MD, Maria Efthymiou ${ }^{4} \mathrm{PhD}$, David A. Isenberg ${ }^{1,2}$ MBBS, MD, FRCP, FAMS, Hannah Cohen ${ }^{4,5} \mathrm{MBChB}, \mathrm{MD}, \mathrm{FRCP}, \mathrm{FRCPath}$

1) Centre for Rheumatology, Division of Medicine, University College London, London, UK

2) Department of Rheumatology, University College London Hospitals NHS Foundation Trust, London, UK

3) Università Vita-Salute San Raffaele, Milan, Italy

4) Haemostasis Research Unit, Department of Haematology, University College London, London, UK

5) Department of Haematology, University College London Hospitals NHS Foundation Trust, London, UK

\section{Corresponding author:}

David A. Isenberg

Centre for Rheumatology,

University College London

Room 424, $4^{\text {th }}$ Floor Rayne Building,

5 University Street,

London WC1E 6JF, UK.

E-mail: d.isenberg@ucl.ac.uk 


\section{ABSTRACT}

Cerebral and cardiovascular ischaemic events are frequent complications of systemic lupus erythematosus (SLE) and constitute primary causes of permanent damage. However, the pathogenic determinants of an increased thromboembolic risk in patients with SLE are only partially understood. Atherosclerosis constitutes a fertile soil for the development of thrombosis and shows disproportionately high prevalence and progression rates in patients with SLE. Antiphospholipid antibodies are independent risk factors for acute thrombosis, but can also prompt long-term vascular inflammation. Aberrant interactions among immune cells and dysfunctions in the deployment of the coagulation cascade have historically less been explored in SLE, but recent evidence suggests they can also play a critical role at the crossroads between inflammation and haemostasis. In this review, we discuss how different pro-thrombotic mechanisms can be prompted by and synergise with SLEspecific pathogenic events and speculate about novel potential directions for research and drug development.

KEYWORDS: systemic lupus erythematosus, thrombosis, thromboembolism, ischaemia, cardiovascular risk, antiphospholipid antibodies, coagulation, protein $\mathrm{C}$, atherosclerosis, innate immunity

\section{KEY MESSAGES}

- Patients with SLE have an increased thromboembolic risk

- Antiphospholipid antibodies and accelerated atherosclerosis constitute established risk factors for thrombosis in patients with SLE

- Dysfunctional coagulation cascade and innate immune responses may also promote thrombophilia and inflammation in SLE 


\section{INTRODUCTION}

Systemic lupus erythematosus (SLE) is a multifactorial, autoimmune rheumatic disease with a peak incidence in females during early adulthood. From a pathogenic perspective, SLE results from a wide range of inherited and acquired factors, which combine to disturb the physiological immune response at different levels. Clinically, this complexity is evident from the significant phenotype heterogeneity, which in turn impairs the capacity to develop effective treatments for large numbers of patients. Thus, despite significant advances in the control of the inflammatory manifestations, that are usually identified as hallmarks of the disease, we still lack knowledge of key individual pathogenic mechanisms that link SLE to increased overall mortality and reduced quality of life [1, 2].

Cerebral and cardiovascular ischaemic events are major causes of irreversible damage and death in patients with SLE [3-5]. SLE-associated pregnancy complications and non-cerebrovascular neurological features constitute additional major causes of morbidity and, interestingly, potential manifestations of vascular dysfunction [6,7]. Patients with SLE show an increased cardiovascular risk and develop thromboembolic events earlier [8-10], compared to age-matched controls from the general population and to patients with other immune-mediated diseases [11, 12]. Furthermore, SLE constitutes an independent risk factor for mortality and impaired recovery after an ischaemic event [4, 13]. Cerebral and cardiovascular events can complicate the underlying inflammatory disease at any time, but the early stages of the disease seem to be associated with a higher age-adjusted risk of vascular complications [14-16]. Nonetheless, the excess prevalence of ischaemic manifestations in patients with SLE increases with time in comparison to control subjects [17]. Arterial ischaemic events are more frequent [18] and occur with an estimated probability of $5.1-8.5 \%$ within five years from diagnosis [19]. In addition, venous events are relatively frequent in patients with SLE (five-year probability 3.7-10.3\% according to ethnicity [19]), who show a 4.5-12.7-fold increased risk of deep venous thrombosis and a 3.0-19.7-fold increased risk of pulmonary embolism, compared to the general population $[20,21]$. The reasons for a disproportionate thromboembolic risk in patients with SLE are only partially understood, but seem to involve different pathogenic mechanisms such as accelerated atherosclerosis, antiphospolipid antibodies (aPL), abnormal interactions between platelets, leukocytes and the endothelium and aberrant activation of the coagulation cascade (Figure 
1). Aseptic endocarditis and, in particular, Libman-Sacks' endocarditis can affect up to $31 \%$ of patients with SLE and constitute additional potential causes of embolism [22]. In this review, we discuss the most recent evidence describing the susceptibility of patients with SLE to the development of thromboembolic ischemic events and speculate about possible future directions for investigation of pathogenic mechanisms and therapeutic intervention.

\section{ACCELERATED ATHEROSCLEROSIS}

The rupture of an atherosclerotic plaque is a major cause of thromboembolism and subsequent cardiac, cerebral or limb ischemia. Atherosclerosis has a high prevalence in patients with SLE, according to clinical and post-mortem studies [16, 23]. Potential factors accounting for an increased atherosclerotic risk in patients with SLE include inflammation-induced vessel dysfunction and increased prevalence of conventional cardiovascular risk factors (Figure 2) [24, 25]. Diseasespecific inflammatory events probably synergise with traditional drivers of atheroma formation and with the side effects of corticosteroids and other treatments.

T-cells are major drivers of SLE pathogenesis [26]. Imbalances between effector and regulatory T-cell functions can account for disease flares and for accelerated vascular injury [27]. However, growing evidence supports a role of innate immunity in impairing the vascular response to flow-related or metabolic stressors in patients with SLE. Interferon alpha (IFNa), in particular, is a hallmark of the antiviral-like inflammatory response that drives disease flares at least in a subset of patients with SLE $[28,29]$. IFNa impairs the maintenance tasks of endothelial progenitor cells and favours the local differentiation of macrophages into foam cells [30, 31]. Complement activation may also be associated with endothelial inflammation and subsequent leukocyte recruitment at sites of vascular atherogenic inflammation. Furthermore, complement deposition can be detected in vascular atherosclerotic lesions from patients with SLE [32].

The significance of traditional cardiovascular risk factors seems to vary among different SLE cohorts, possibly reflecting differences in lifestyles among different populations and/or historical changes in treatment strategies. More consistently, patients with SLE show a higher prevalence of hypertension [17], which in turn associates with cardiovascular events, pregnancy complications and 
mortality [16, 33, 34]. Diabetes and sedentary habits are also more frequent in patients with SLE, although their specific role in SLE as clinical predictors of atherosclerosis is less clear [16, 17]. Quantitative data on lipid profile in SLE are conflicting and do not clearly support a disproportionate prevalence of hyperlipidaemia in patients with SLE $[17,34]$. In contrast, qualitative data indicate a sinister increase in pro-atherogenic oxidised lipoproteins during active disease [35-37], pointing to a major role for inflammation-induced oxidative stress in perturbing lipid metabolism and causing subsequent vascular injury in SLE [38]. In accordance with a unique pathophysiological background, patients with SLE show a distinctive pattern of vascular injury characterised by focal, rapidly growing and highly unstable lesions rather than generalised vessel wall thickening [39-42]. Plaque formation in SLE may represent an accelerated mis-repair response to a primary vascular injury, possibly favoured by concomitant "surges" in cellular and humoral inflammatory mediators (perhaps linked to disease flares) as well as in oxidative stress [27, 40, 43]. In addition, the vascular damage in SLE not only involves large arterial vessels, but also the microcirculation, thus further enhancing the risk of ischemic events [44].

\section{ANTIPHOSPHOLIPID ANTIBODIES}

Antiphospholipid antibodies are part of the spectrum of SLE-related serological abnormalities and detectable in up to $40 \%$ of patients [19]. Clinically significant aPL are those that are persistently positive, i.e. present on two occasions at least 12 weeks apart. Antiphospholipid syndrome (APS) is defined as persistent aPL associated with thrombosis (arterial, venous or microvascular) or pregnancy morbidity according to the International consensus criteria [45]. Catastrophic APS (CAPS) is defined as the simultaneous occurrence of APS manifestations in three or more organs, systems or tissues and confirmed by finding microthrombosis at biopsy [46]. APS occurs in approximately $15 \%$ of SLE patients [47] and can also be found in other inflammatory diseases or as a stand-alone disorder (primary APS). CAPS has a $1 \%$ prevalence in patients with APS [46]. Routine aPL screening conventionally [45] involves testing for lupus anticoagulant (LA) and measuring the titres of IgG and IgM anticardiolipin (aCL) and anti-beta2-glycoprotein I (aß2GPI) antibodies. Beta2glycoprotein I constitutes the main antigenic counterpart of aPL, although other potential ligands 
have been identified (Figure 3). The physiological role of $\beta 2 \mathrm{GPI}$ is only partially understood and includes scavenging microparticles and pyrogens from the circulation, trimming the activation of the coagulation cascade and interacting with the endothelium and circulating cells $[48,49]$. In particular, in vitro studies suggest that Toll-like receptor (TLR) 4 and annexin A2 (a phospholipid-binding protein involved in endothelial activation and in the regulation of the coagulation cascade), possibly through reciprocal interactions, behave as $\beta 2 \mathrm{GPI}$ cell surface receptors and promote activation of the endothelium as well as of circulating leukocytes and platelets [50]. TLR 1, 2, 6 and apolipoprotein E receptor 2 might also redundantly recognise $\beta 2 \mathrm{GPI}$ on the cell surface [50-52].

Antiphospholipid antibodies can bind to different epitopes on the pentameric tridimensional structure of $\beta 2 \mathrm{GPI}$. Domain I of $\beta 2 \mathrm{GPI}$ contains the immunodominant epitope for clinically relevant aPL. However, this epitope is only exposed when $\beta 2$ GPI binds to anionic surfaces, losing its default closed circular conformation and enabling antibody binding [49]. Among the non-criteria aPL, antiannexin A5 (AnxA5) antibodies have also been detected in patients with APS [53]. AnxA5 forms organised structures on surface phospholipids, providing an anticoagulant shield against tissue factor (TF)-dependent coagulation progression [50]. Anti-AnxA5 antibodies might interfere with this mechanism, thus favouring thrombosis, but their clinical significance is controversial [54]. Antibodies targeting prothrombin or the phosphatidylserine-prothrombin complex (aPS/PT) may show better promise as diagnostic and prognostic markers in APS. In particular, aPS/PT appear to be associated with increased thrombotic risk [55-58], SLE-related neuropsychiatric manifestations [59] and pregnancy morbidity $[57,60,61]$. The pathogenic mechanism underlying these clinical manifestations is also unknown. Recently, following previous evidence of impaired protein C activity in association with aPL positivity and APS [62-66], anti-protein C antibodies have been added to the APS serological repertoire [67].

Thromboembolic events do not occur in all persistently positive aPL patients. In fact, though aPL induce a prothrombotic environment, additional factors are required to trigger and sustain activation of the coagulation cascade leading to thromboembolic events. Constitutional variables include congenital abnormalities in coagulation factors or acquired pro-thrombotic conditions such as neoplasia. Situational, environmental or host-related factors such as infections, traumas, ongoing 
surgery, pregnancy, exogenous estrogens, smoking and flares of an underlying inflammatory disease can provide the so-called second hit for aPL-mediated progression to thrombosis. Endothelial priming plays a crucial role in the recruitment of clotting factors. Inflammatory stimuli such as lipopolysaccharide (LPS) are able to provide this initiating input. Interestingly, LPS-induced upregulation of TLR4 favours $\beta 2$ GPI docking to the vessel walls, possibly also enhancing aPL/ $\beta 2$ GPI binding [50]. Linearization of $\beta 2 \mathrm{GPI}$ and exposure of domain I is another rate limiting step in the pathogenesis of aPL-induced thrombosis. Oxidation might play a role in this setting [68] as oxidised $\beta 2 \mathrm{GPI}$ is bound more strongly by aß2GPI in vitro [69]. Accordingly, patients with APS at higher clinical risk show increased levels of oxidised $\beta 2 \mathrm{GPI}$, higher titres of anti-domain I antibodies and higher markers of oxidative stress [70]. Complement is also crucial to foster endothelial as well as platelet and leukocyte activation towards thrombosis [71]. Thrombotic microangiopathy (TMA), characterised by extensive endothelial injury, decreased coagulation factors and platelet levels, traumatic haemolysis and multi-organ injury, constitutes an extreme phenotype in the spectrum of deranged complement activation and can be part of the clinical manifestations of APS [72].

Acute thrombosis represents the most devastating manifestation of aPL in patients with APS, with or without SLE. However, mechanistic studies suggest that aPL also promote long-term vessel remodelling $[55,73]$. These pathogenic events have a prominent role in aPL-related nephropathy $[73,74]$, which can account for up to $14 \%$ of cases of SLE with renal involvement and eventually cause nephrovascular hypertension [75]. Furthermore, chronic aPL-induced vascular injury is a potential co-factor in the development of atherosclerosis in patients with SLE [31]. Similar to patients with SLE [76], patients with APS also show an IFN-mediated impairment of endothelial turnover which might promote plaque destabilisation [77].

\section{PLATELETS, LEUKOCYTES AND THE ENDOTHELIUM}

Endothelial cells, leukocytes and platelets interact productively to ensure vessel integrity. These first line innate immune cells sense the presence of potential septic or non-septic threats within the circulating blood and activate a complex set of stereotyped responses, which in turn promote inflammation and thrombosis [78, 79]. Platelets, in particular, are involved in a wide range of 
inflammatory tasks beyond their most obvious role in haemostasis (Figure 4). After recognition of invading pathogens through innate (TLR) or adaptive ( $F c \gamma, \varepsilon R)$ immune receptors, platelets promote endothelial and leukocyte activation locally, through direct cell-cell interactions, or systemically, due to release of microparticles. Platelet-derived microparticles (PMP) are shed from platelet cell surface following activation and constitute the bulk of circulating microparticles in humans [80]. Constitutive activation of platelets and persistently high levels of PMP are thought to characterise autoimmune diseases and affect disease activity, vessel integrity and thrombotic risk [81-84]. Platelets further contribute to long-term vessel remodelling by releasing growth factors and mitogens [85].

Platelets may have a fundamental role as inflammatory partners of neutrophils [86]. In fact, platelets can trigger neutrophil activation, extend neutrophil lifespan and prompt the generation of neutrophil extracellular traps (NETs) [87, 88]. These aggregates of decondensed chromatin concentrate high amounts of crucial autoantigens for the pathogenesis of SLE and coagulation triggers such as TF or von Willebrand factor (vWF) [89]. NETs further contribute to thrombosis by neutralising tissue factor pathway inhibitor (TFPI) and activating factor XII [90]. Recently, a noncanonical mechanism of vascular occlusion due to uncontrolled NET formation has been described [91]. Interestingly, this phenomenon was dependent on DNAses, which are preferential SLE autoantigens [92]. Neutrophils from patients with SLE have also been shown to undermine endothelial integrity under inflammatory conditions and to contribute to atherosclerosis by enhancing cholesterol-induced innate responses and by promoting IFNa production [31, 93-95]. Deranged platelet-leukocyte interactions and/or NETosis are also detectable in rheumatoid arthritis, antineutrophil cytoplasmic antibody (ANCA)-associated vasculitides, APS and even diabetes, which all share an enhanced thrombotic risk [96-98]. Intriguingly, aPL induce NETs, which in turn are also able to promote thrombin generation. This phenomenon is apparently more evident with aß2GPI and is dependent on the formation of reactive oxygen species and on platelet/endothelial TLR4 [99]. Conversely, heparin contrasts the formation of NETs [100]. NETs have also been detected within coronary thrombi and can contribute to plaque destabilisation in atherosclerosis [101].

The activation of the endothelium is a pivotal pathogenic event at the crossroads between inflammation and thrombosis, as it involves the expression of leukocyte adhesion molecules such 
as P-selectin and, later on, E-selectin, vascular cell adhesion molecule 1 (VCAM1) and intercellular adhesion molecules (ICAMs) as well as coagulation triggers such as TF and vWF. Furthermore, similar to platelets and other circulating cells, the endothelium is endowed with the ability to release signalling quanta through microparticles and has a major role in the control of the vascular tone. Endothelial activation and vasomotor dysfunction, possibly favoured by IFNa-prominent responses, are hallmarks of SLE and may account for part of the SLE-related cardiovascular risk [76]. Moreover, endothelium-derived microparticles (EMP) constitute the prevalent microparticle subset in patients with SLE and can promote dendritic cell activation and NETosis [83, 102].

\section{DYSFUNCTIONAL COAGULATION CASCADE}

Clinical and biological evidence suggests the existence of extensive connections between haemostasis and inflammation [90]. Thus, not surprisingly, alterations in the deployment of the coagulation cascade constitute a distinctive feature of patients with inflammatory diseases such as SLE (Figure 5) [81, 103-105]. Enhanced activation of TF pathway can, intuitively, be linked to increased inflammation-induced TF expression on endothelial cells, neutrophils, eosinophils and other cells [89, 101] and has been consistently detected in SLE [106]. However, impaired TFPI function has also been proposed as a potential pro-thrombotic mechanism in patients with SLE and in patients with APS. Circulating TFPI levels are affected by disease activity $[105,107]$ and by the generation of NETs [90]. In addition, TFPI can be inhibited by aß2GPI [108]. Nonetheless, conflicting results have been reported on TFPI concentrations in SLE under resting conditions in comparison to healthy subjects $[105,107,109]$. In addition to TFPI, the plasmin system and the

thrombomodulin/protein $\mathrm{C} /$ protein $\mathrm{S}$ system concur to physiologically regulate the coagulation cascade. Activation of protein $\mathrm{C}$ during the coagulation cascade is crucial to counterbalance the prothrombotic effects of thrombin generation, with factor Va and VIIla inactivation by activated protein C (APC) effectively preventing thrombin formation [110]. Interestingly, in addition to its role as an anticoagulant, protein $\mathrm{C}$ is also an anti-inflammatory mediator. APC exerts an endothelial protein C receptor (EPCR)-dependent cytoprotective effect on the endothelium (as well as on 
glomerular podocytes), through cleavage of protease activated receptor 1 [111]. Furthermore, it inhibits the formation of NETs [112].

Thrombin generation (TG) via the TF pathway is integral to the blood coagulation process and TG analysis provides a global measure of coagulation dynamics and an individual's thrombogenic potential [113-115]. Two studies reported that generation of thrombin in SLE patients under platelet-free conditions was either delayed [103] or less extensive [104] than in controls, which apparently contrasts with the increased thrombotic risk of these patients. Notably, in the latter study the results were not affected by the aPL profile, thus ruling out an exclusive LA effect and supporting the idea that multiple biological factors might account for the unique SLE haemostatic phenotype [104]. By contrast, Pereira et al. took into consideration the amount of PMP in platelet-free plasma and found that TG was dependent on PMP. In addition, the levels of PMP correlated with the ability of plasma to generate thrombin. Since patients with SLE had higher concentrations of circulating PMP, they also showed a higher endogenous thrombin potential (ETP) [81]. More recently, Arachchillage et al. demonstrated that high-avidity anti-protein $\mathrm{C}$ antibodies were associated with greater resistance to both endogenous and exogenous protein $\mathrm{C}$ and with a severe APS thrombotic phenotype (defined as the development of recurrent VTE while patients were receiving therapeutic anticoagulation or both venous and arterial thrombosis), suggesting their potential use as prognostic markers in APS [67].

Besides APS, acquired APCr has also been reported in SLE. In particular, Oosting and colleagues described the ability of some aPL extracted from patients with SLE to dampen APCmediated inactivation of activated factor $\mathrm{V}$ with variable dependency on the presence of protein $\mathrm{S}$ [62]. Nojima et al. later reported a $34.4 \%$ prevalence of acquired APCr in patients with SLE and found a strong association with venous thromboembolism and with coexisting LA and antiprothrombin antibodies [65]. The same group also described additional associations with aPS/PT, aß2GPI and anti-protein S antibodies [63, 64]. Little is known about the role of anti-protein C antibodies and APCr in SLE.

Besides being favoured by inflammation, the generation of thrombin, in turn, affects the activation state of a wide range of cells involved in inflammation, such as the endothelium, circulating 
platelets and even mast-cells [116-118]. Thrombin is also able to bypass the conventional ways of initiation of the complement cascade and to favour the generation of C5a and C5b [119]. High levels of anaphylotoxins, such as C5a, affect the activation status of the endothelium, platelets and leukocytes, ultimately promoting thrombosis through the expression of TF and increasing vascular permeability. Thrombin-induced shredding of C5 also leads to the formation of the complement membrane attack complex, which either causes direct endothelial damage or promotes long-term inflammation through its inactive form [120]. Accordingly, anticoagulation prompts substantial changes in complement activation status [121]. Similarly, $\mathrm{C} 1$ inhibitor $(\mathrm{C} 1 \mathrm{INH})$, one of the main physiological regulators of the complement cascade can also inhibit the coagulation system [122]. Patients with SLE and thrombotic events constitutionally show reduced $\mathrm{C} 1 \mathrm{INH}$ - activated factor XII complexes, suggesting the presence of disease-related alterations in the activation of the contact system [123]. The presence of shared activation pathways between the coagulation cascade and other key cellular of humoral players in the pathophysiology of SLE suggests that imbalances in haemostasis could, epiphenomenally, represent or pathogenically affect SLE-related manifestations other than overt thrombosis.

\section{CLINICAL IMPLICATIONS}

\section{Tools for ischaemic risk assessment in SLE}

The Framingham risk equations are widely used to estimate the 10-year risk for coronary artery disease, stroke or cardiovascular disease in the general population. With respect to the general cardiovascular outcome, age, gender, history of smoking or diabetes, systolic blood pressure and antihypertensive treatments, total cholesterol and high-density lipoprotein levels constitute relevant predictive variables [124]. However, cardiovascular risk estimate according to traditional factors fails to capture the whole population of patients with SLE that will eventually develop a cardiovascular event [125]. Accordingly, attempts have been undertaken to integrate SLE-specific clinical parameters of potential relevance for thromboembolic diseases into the Framingham core of risk factors. A score combining antiphospholipid-related with conventional cardiovascular risk factors has been developed in APS and validated in small cohorts of patients with SLE and APS. In 
particular, the Global Anti-Phospholipid Syndrome (GAPSS) score takes into consideration the presence of arterial hypertension, hyperlipidaemia and positive serology for aCL, anti- $\beta 2 \mathrm{GPI}$, LA and/or anti-PS/PT [126]. Similar algorithms, which also consider disease activity markers, have been developed retrospectively in large SLE cohorts, but only partially validated [127, 128]. Recently, Urowitz et al. reported that assigning double values to each Framingham item, consistently predicts the development of coronary artery disease in patients with SLE [129]. Currently, there is no SLEspecific score for assessing the risk of venous thromboembolism [130]. Genetic determinants of increased thrombotic risk seem to affect the risk of venous events independently [131], while acquired factors such as cancer, renal failure or aPL (especially LA) might play a synergistic role in SLE, suggesting that patients with those comorbidities should be assigned to a high-risk category $[21,130,132]$.

\section{Current status and perspectives for therapeutic interventions}

Taken together, the data so far presented confirm that heterogeneity is a hallmark of the pathogenic events that underlie the development of SLE and in particular of its cardiovascular complications. There is a notable lack of prospective trials aimed at assessing the potential benefit of specific interventions for preventing the development of ischemic complications in SLE. A trial on the role of pioglitazone, a peroxisome proliferator-activated receptor gamma agonist, in vascular prevention in SLE is ongoing (NCT02338999). More consistent evidence has been acquired on the role of anticoagulants in patients with APS. In particular, according to the available data, patients with thrombotic APS generally require lifelong anticoagulation [133-135]. Warfarin has long been the mainstay of treatment in this setting. However, the recent RAPS trial reported that in APS patients with venous thromboembolism and a target INR range of $2.0-3.0$, rivaroxaban, a direct oral anticoagulant (DOAC), might offer the potential to be an effective, safe and convenient alternative to warfarin [136]. However, since the RAPS study employed a surrogate laboratory marker of pharmacological efficacy and did not met the primary endpoint (less than $20 \%$ inferiority in reduction of the endogenous thrombin potential, compared to warfarin), further clinical trials with clinical end points would aid in defining the role of DOACs in APS. Despite the advances in the setting of APS, 
there is still a significant area of uncertainty with respect to the treatment of both criteria as well as non-criteria APS manifestations such as aseptic endocarditis [133]. In addition, little is known about the optimal strategies to combat the most severe manifestations of APS, such as CAPS and TMA $[46,137]$. In the acute phase of CAPS, removal or neutralisation of pathogenic autoantibodies can be achieved by plasma exchange or intravenous immunoglobulins in addition to glucocorticoids and alternatively to conventional immunosuppressants [137]. Rituximab could play a role in maintaining remission and improving survival in the long-term [138]. Similar strategies can be employed for refractory thrombotic APS [134]. Intravenous immunoglobulins, or the anti-C5 antibody eculizumab, can be useful in complement-driven conditions such as TMA. Novel therapies including decoy $\beta 2$ GPI domains have also been proposed [50, 134]. According to a recent meta-analysis, aspirin has a clinically relevant prophylactic role in patients with SLE who are asymptomatic carriers of aPL [139].

Anti-malarials such as hydroxychloroquine constitute the backbone treatment for patients with connective tissue diseases and have a robustly established role in SLE to increase overall survival and prevent disease flare. In addition, anti-malarials might reduce low-density lipoprotein levels [140] and (especially in combination with low-dose aspirin [141]) have a protective effect against thrombosis in SLE and APS although the evidence at this regard is at least in part conflicting $[142,143]$.

Given the increased prevalence of traditional cardiovascular risk factors in SLE, aggressive control of hypertension, lipid profile, diabetes, smoking and other lifestyle habits might be rewarding. Preliminary data from large inception cohorts apparently confirm this idea [17]. Statins constitute the mainstay of treatment in dyslipidaemic patients at increased risk of atherosclerosis. Furthermore, statins might also exert non-metabolic, immunoregulatory effects such as enhanced T-regulatory function or reduced oxidative stress in monocytes besides protection from atherosclerosis [144-147]. Statins may also behave in synergy with anti-malarials to dampen IFNa-related responses [148]. Similar pleiotropic effects have also been observed with metformin, a widely used antidiabetic drug [149].

However, these agents have probably limited effect on the main pathogenic drivers of the disease [150], which also probably comprise a constellation of possible concurring events. The 
presence of pathogenically-distinct subsets of patients in the clinical landscape of SLE [28], highlights the need for individualised treatment approaches.

\section{CONCLUSION}

Patients with SLE have a disproportionate thromboembolic risk throughout their life. Deranged intravascular and systemic immune homeostasis probably synergise with the side-effects of drugs and with traditional cardiovascular risk factors to promote long-term vascular injury and acute thrombosis. The spectrum of potentially concurring factors in this setting is extremely broad and only partially understood as each patient with SLE represents a unique combination of multiple pathogenic events. Therefore, individualised patient-tailored treatments, possibly based on the prevalent pathogenic profile, constitute the most promising strategy for the future.

FUNDING STATEMENT: DAI recognises the support of the University College Hospital / University College London Biomedical Centre Award.

CONFLICT OF INTEREST STATEMENT: The authors declare that there is no conflict of interest in connection with this work. 


\section{REFERENCES}

1 Tektonidou MG, Wang Z, Ward MM. Brief Report: Trends in Hospitalizations Due to Acute Coronary Syndromes and Stroke in Patients With Systemic Lupus Erythematosus, 1996 to 2012. Arthritis \& rheumatology 2016;68(11):2680-5.

2 Bakshi J, Segura BT, Wincup C, Rahman A. Unmet Needs in the Pathogenesis and Treatment of Systemic Lupus Erythematosus. Clinical reviews in allergy \& immunology 2017.

3 Pego-Reigosa JM, Lois-Iglesias A, Rua-Figueroa I, et al. Relationship between damage clustering and mortality in systemic lupus erythematosus in early and late stages of the disease: cluster analyses in a large cohort from the Spanish Society of Rheumatology Lupus Registry. Rheumatology 2016;55(7):1243-50.

4 Rossides M, Simard JF, Svenungsson E, von Euler M, Arkema EV. Mortality and Functionality after Stroke in Patients with Systemic Lupus Erythematosus. J Rheumatol 2017;44(11):1590-6.

5 Nossent J, Cikes N, Kiss E, et al. Current causes of death in systemic lupus erythematosus in Europe, 2000--2004: relation to disease activity and damage accrual. Lupus 2007;16(5):309-17.

6 Cohen D, Rijnink EC, Nabuurs RJ, et al. Brain histopathology in patients with systemic lupus erythematosus: identification of lesions associated with clinical neuropsychiatric lupus syndromes and the role of complement. Rheumatology (Oxford) 2017;56(1):77-86.

7 Rai R. Is miscarriage a coagulopathy? Current opinion in obstetrics \& gynecology 2003;15(3):265-8.

8 Holmqvist M, Simard JF, Asplund K, Arkema EV. Stroke in systemic lupus erythematosus: a metaanalysis of population-based cohort studies. RMD open 2015;1(1):e000168.

9 Scalzi LV, Hollenbeak CS, Wang L. Racial disparities in age at time of cardiovascular events and cardiovascular-related death in patients with systemic lupus erythematosus. Arthritis Rheum 2010;62(9):2767-75.

10 Bessant R, Hingorani A, Patel L, MacGregor A, Isenberg DA, Rahman A. Risk of coronary heart disease and stroke in a large British cohort of patients with systemic lupus erythematosus. Rheumatology (Oxford) 2004;43(7):924-9.

11 Fernandez-Gutierrez B, Perrotti PP, Gisbert JP, et al. Cardiovascular disease in immune-mediated inflammatory diseases: A cross-sectional analysis of 6 cohorts. Medicine (Baltimore) 2017;96(26):e7308.

12 Lee JJ, Pope JE. A meta-analysis of the risk of venous thromboembolism in inflammatory rheumatic diseases. Arthritis Res Ther 2014;16(5):435.

13 Bundhun PK, Boodhoo KD, Long MY, Chen MH. Impact of Antiphospholipid Syndrome and/or Systemic Lupus Erythematosus on the Long-term Adverse Cardiovascular Outcomes in Patients After Percutaneous Coronary Intervention: A Systematic Review and Meta-analysis. Medicine (Baltimore) 2016;95(12):e3200.

14 Avina-Zubieta JA, To F, Vostretsova K, De Vera M, Sayre EC, Esdaile JM. Risk of Myocardial Infarction and Stroke in Newly Diagnosed Systemic Lupus Erythematosus: A General Population-Based Study. Arthritis Care Res (Hoboken) 2017;69(6):849-56.

15 Urowitz MB, Gladman DD, Ibanez D, et al. Evolution of disease burden over five years in a multicenter inception systemic lupus erythematosus cohort. Arthritis Care Res (Hoboken) 2012;64(1):132-7.

16 Symmons DP, Gabriel SE. Epidemiology of CVD in rheumatic disease, with a focus on RA and SLE. Nat Rev Rheumatol 2011;7(7):399-408.

17 Tselios K, Gladman DD, Su J, Ace O, Urowitz MB. Evolution of Risk Factors for Atherosclerotic Cardiovascular Events in Systemic Lupus Erythematosus: A Longterm Prospective Study. J Rheumatol 2017.

18 Sarabi ZS, Chang E, Bobba $\mathrm{R}$, et al. Incidence rates of arterial and venous thrombosis after diagnosis of systemic lupus erythematosus. Arthritis Rheum 2005;53(4):609-12.

19 Mok CC, Tang SS, To CH, Petri M. Incidence and risk factors of thromboembolism in systemic lupus erythematosus: a comparison of three ethnic groups. Arthritis Rheum 2005;52(9):2774-82.

20 Avina-Zubieta JA, Vostretsova K, De Vera MA, Sayre EC, Choi HK. The risk of pulmonary embolism and deep venous thrombosis in systemic lupus erythematosus: A general population-based study. Semin Arthritis Rheum 2015;45(2):195-201.

21 Chung WS, Lin CL, Chang SN, Lu CC, Kao CH. Systemic lupus erythematosus increases the risks of deep vein thrombosis and pulmonary embolism: a nationwide cohort study. J Thromb Haemost 2014;12(4):452-8. 
22 Vivero F, Gonzalez-Echavarri C, Ruiz-Estevez B, Maderuelo I, Ruiz-Irastorza G. Prevalence and predictors of valvular heart disease in patients with systemic lupus erythematosus. Autoimmun Rev 2016;15(12):1134-40.

23 Jain D, Halushka MK. Cardiac pathology of systemic lupus erythematosus. J Clin Pathol 2009;62(7):584-92.

24 Haque S, Gordon C, Isenberg D, et al. Risk factors for clinical coronary heart disease in systemic lupus erythematosus: the lupus and atherosclerosis evaluation of risk (LASER) study. J Rheumatol 2010;37(2):3229.

25 Chung CP, Avalos I, Oeser A, et al. High prevalence of the metabolic syndrome in patients with systemic lupus erythematosus: association with disease characteristics and cardiovascular risk factors. Ann Rheum Dis 2007;66(2):208-14.

26 Rother N, van der Vlag J. Disturbed T Cell Signaling and Altered Th17 and Regulatory T Cell Subsets in the Pathogenesis of Systemic Lupus Erythematosus. Frontiers in immunology 2015;6:610.

27 Baragetti A, Ramirez G, Magnoni M, et al. Disease Trends Over Time and CD4+ CCR5+ T-Cells Expansion Predict Carotid Atherosclerosis Development in Patients with Systemic Lupus Erythematosus. Nutrition, Metabolism and Cardiovascular Diseases 2017.

28 Banchereau R, Hong S, Cantarel B, et al. Personalized Immunomonitoring Uncovers Molecular Networks that Stratify Lupus Patients. Cell 2016;165(6):1548-50.

29 Furie R, Khamashta M, Merrill JT, et al. Anifrolumab, an Anti-Interferon-alpha Receptor Monoclonal Antibody, in Moderate-to-Severe Systemic Lupus Erythematosus. Arthritis \& rheumatology 2017;69(2):37686.

30 Denny MF, Thacker S, Mehta $\mathrm{H}$, et al. Interferon-alpha promotes abnormal vasculogenesis in lupus: a potential pathway for premature atherosclerosis. Blood 2007;110(8):2907-15.

31 Lewandowski LB, Kaplan MJ. Update on cardiovascular disease in lupus. Current opinion in rheumatology 2016;28(5):468-76.

32 Shields KJ, Mollnes TE, Eidet JR, et al. Plasma complement and vascular complement deposition in patients with coronary artery disease with and without inflammatory rheumatic diseases. PLoS One 2017;12(3):e0174577.

33 Canti V, Maggio L, Ramirez GA, et al. Hypertension negatively affects the pregnancy outcome in patients with antiphospholipid syndrome. Lupus 2012;21(7):810-2.

34 Petri M, Perez-Gutthann S, Spence D, Hochberg MC. Risk factors for coronary artery disease in patients with systemic lupus erythematosus. Am J Med 1992;93(5):513-9.

35 Batuca JR, Ames PR, Amaral M, Favas C, Isenberg DA, Delgado Alves J. Anti-atherogenic and antiinflammatory properties of high-density lipoprotein are affected by specific antibodies in systemic lupus erythematosus. Rheumatology (Oxford) 2009;48(1):26-31.

36 O'Neill SG, Giles I, Lambrianides A, et al. Antibodies to apolipoprotein A-I, high-density lipoprotein, and $C$-reactive protein are associated with disease activity in patients with systemic lupus erythematosus. Arthritis Rheum 2010;62(3):845-54.

37 Pego-Reigosa JM, Lu TY, Fontanillo MF, del Campo-Perez V, Rahman A, Isenberg DA. Long-term improvement of lipid profile in patients with refractory systemic lupus erythematosus treated with B-cell depletion therapy: a retrospective observational study. Rheumatology (Oxford) 2010;49(4):691-6.

38 Yilmaz S, Caliskan M, Kulaksizoglu S, et al. Association between serum total antioxidant status and coronary microvascular functions in patients with SLE. Echocardiography 2012;29(10):1218-23.

39 Kay SD, Poulsen MK, Diederichsen AC, Voss A. Coronary, Carotid, and Lower-extremity Atherosclerosis and Their Interrelationship in Danish Patients with Systemic Lupus Erythematosus. J Rheumatol 2016;43(2):315-22.

40 Mason JC. Cytoprotective pathways in the vascular endothelium. Do they represent a viable therapeutic target? Vascular pharmacology 2016;86:41-52.

41 Roman MJ, Crow MK, Lockshin MD, et al. Rate and determinants of progression of atherosclerosis in systemic lupus erythematosus. Arthritis Rheum 2007;56(10):3412-9.

42 El-Magadmi M, Bodill H, Ahmad Y, et al. Systemic lupus erythematosus: an independent risk factor for endothelial dysfunction in women. Circulation 2004;110(4):399-404. 
43 Gaal K, Tarr T, Lorincz H, et al. High-density lipopoprotein antioxidant capacity, subpopulation distribution and paraoxonase-1 activity in patients with systemic lupus erythematosus. Lipids in health and disease 2016;15:60.

44 Recio-Mayoral A, Mason JC, Kaski JC, Rubens MB, Harari OA, Camici PG. Chronic inflammation and coronary microvascular dysfunction in patients without risk factors for coronary artery disease. Eur Heart $\mathrm{J}$ 2009;30(15):1837-43.

45 Miyakis $S$, Lockshin MD, Atsumi T, et al. International consensus statement on an update of the classification criteria for definite antiphospholipid syndrome (APS). J Thromb Haemost 2006;4(2):295-306.

46 Cervera R, Rodriguez-Pinto I, Colafrancesco S, et al. 14th International Congress on Antiphospholipid Antibodies Task Force Report on Catastrophic Antiphospholipid Syndrome. Autoimmun Rev 2014;13(7):699707.

47 Ruiz-Irastorza G, Egurbide MV, Ugalde J, Aguirre C. High impact of antiphospholipid syndrome on irreversible organ damage and survival of patients with systemic lupus erythematosus. Arch Intern Med 2004;164(1):77-82.

48 Rahgozar S, Giannakopoulos B, Yan X, et al. Beta2-glycoprotein I protects thrombin from inhibition by heparin cofactor II: potentiation of this effect in the presence of anti-beta2-glycoprotein I autoantibodies. Arthritis and rheumatism 2008;58(4):1146-55.

49 de Groot PG, Meijers JC. beta(2) -Glycoprotein I: evolution, structure and function. Journal of thrombosis and haemostasis : JTH 2011;9(7):1275-84.

50 Chighizola CB, Raschi E, Borghi MO, Meroni PL. Update on the pathogenesis and treatment of the antiphospholipid syndrome. Current opinion in rheumatology 2015;27(5):476-82.

51 Ulrich V, Gelber SE, Vukelic M, et al. ApoE Receptor 2 Mediation of Trophoblast Dysfunction and Pregnancy Complications Induced by Antiphospholipid Antibodies in Mice. Arthritis \& rheumatology 2016;68(3):730-9.

52 Zhang W, Gao F, Lu D, et al. Anti-beta2 glycoprotein I antibodies in complex with beta2 glycoprotein I induce platelet activation via two receptors: apolipoprotein E receptor 2 ' and glycoprotein I balpha. Frontiers of medicine 2016;10(1):76-84.

53 Rodriguez-Garcia V, Ioannou Y, Fernandez-Nebro A, Isenberg DA, Giles IP. Examining the prevalence of non-criteria anti-phospholipid antibodies in patients with anti-phospholipid syndrome: a systematic review. Rheumatology (Oxford) 2015;54(11):2042-50.

54 Sciascia S, Amigo MC, Roccatello D, Khamashta M. Diagnosing antiphospholipid syndrome: 'extracriteria' manifestations and technical advances. Nat Rev Rheumatol 2017;13(9):548-60.

55 Bertolaccini ML, Sanna G. Recent advances in understanding antiphospholipid syndrome. F1000Research 2016;5:2908.

56 Lee JS, Gu J, Park HS, Yoo HJ, Kim HK. Coexistence of anti-beta2-glycoprotein I domain I and antiphosphatidylserine/prothrombin antibodies suggests strong thrombotic risk. Clin Chem Lab Med 2017;55(6):882-9.

57 Bertolaccini ML, Atsumi T, Koike T, Hughes GR, Khamashta MA. Antiprothrombin antibodies detected in two different assay systems. Prevalence and clinical significance in systemic lupus erythematosus. Thromb Haemost 2005;93(2):289-97.

58 Sciascia S, Murru V, Sanna G, Roccatello D, Khamashta MA, Bertolaccini ML. Clinical accuracy for diagnosis of antiphospholipid syndrome in systemic lupus erythematosus: evaluation of 23 possible combinations of antiphospholipid antibody specificities. J Thromb Haemost 2012;10(12):2512-8.

59 Syuto T, Shimizu A, Takeuchi Y, et al. Association of antiphosphatidylserine/prothrombin antibodies with neuropsychiatric systemic lupus erythematosus. Clin Rheumatol 2009;28(7):841-5.

60 Hoxha A, Mattia E, Tonello M, Grava C, Pengo V, Ruffatti A. Antiphosphatidylserine/prothrombin antibodies as biomarkers to identify severe primary antiphospholipid syndrome. Clin Chem Lab Med 2017;55(6):890-8.

61 Canti V, et al. Antiphosphatidylserine/prothrombin antibodies in patients with anti-phospholipid syndrome with intrauterine growth restriction and preeclampsia. (submitted in revised form). J Rheumatol 2017. 
62 Oosting JD, Derksen RH, Bobbink IW, Hackeng TM, Bouma BN, de Groot PG. Antiphospholipid antibodies directed against a combination of phospholipids with prothrombin, protein $\mathrm{C}$, or protein $\mathrm{S}$ : an explanation for their pathogenic mechanism? Blood 1993;81(10):2618-25.

63 Nojima J, Iwatani Y, Ichihara K, et al. Acquired activated protein C resistance is associated with IgG antibodies to protein $S$ in patients with systemic lupus erythematosus. Thrombosis research 2009;124(1):127-31.

64 Nojima J, Kuratsune $\mathrm{H}$, Suehisa E, Iwatani $\mathrm{Y}$, Kanakura Y. Acquired activated protein $\mathrm{C}$ resistance associated with IgG antibodies against beta2-glycoprotein I and prothrombin as a strong risk factor for venous thromboembolism. Clinical chemistry 2005;51(3):545-52.

65 Nojima J, Kuratsune $\mathrm{H}$, Suehisa $\mathrm{E}$, et al. Acquired activated protein $\mathrm{C}$ resistance is associated with the co-existence of anti-prothrombin antibodies and lupus anticoagulant activity in patients with systemic lupus erythematosus. British journal of haematology 2002;118(2):577-83.

66 Zuily $S$, Regnault $V$, Guillemin F, et al. Superficial vein thrombosis, thrombin generation and activated protein $\mathrm{C}$ resistance as predictors of thromboembolic events in lupus and antiphospholipid patients. A prospective cohort study. Thrombosis research 2013;132(1):e1-7.

67 Arachchillage DR, Efthymiou M, Mackie IJ, Lawrie AS, Machin SJ, Cohen H. Anti-protein C antibodies are associated with resistance to endogenous protein $C$ activation and a severe thrombotic phenotype in antiphospholipid syndrome. J Thromb Haemost 2014;12(11):1801-9.

68 Delgado Alves J, Mason L, Ames PR, et al. Antiphospholipid antibodies are associated with enhanced oxidative stress, decreased plasma nitric oxide and paraoxonase activity in an experimental mouse model. Rheumatology (Oxford) 2005;44(10):1238-44.

69 Raimondo MG, Pericleous C, Radziszewska A, et al. Oxidation of beta2-glycoprotein I associates with IgG antibodies to domain I in patients with antiphospholipid syndrome. PLoS One 2017;12(10):e0186513.

70 Delgado Alves J, Ames PR, Donohue S, et al. Antibodies to high-density lipoprotein and beta2glycoprotein I are inversely correlated with paraoxonase activity in systemic lupus erythematosus and primary antiphospholipid syndrome. Arthritis Rheum 2002;46(10):2686-94.

71 Pierangeli SS, Girardi G, Vega-Ostertag M, Liu X, Espinola RG, Salmon J. Requirement of activation of complement C3 and C5 for antiphospholipid antibody-mediated thrombophilia. Arthritis Rheum 2005;52(7):2120-4.

72 Liszewski MK, Atkinson JP. Too much of a good thing at the site of tissue injury: the instructive example of the complement system predisposing to thrombotic microangiopathy. Hematology Am Soc Hematol Educ Program 2011;2011:9-14.

73 Canaud G, Bienaime F, Tabarin F, et al. Inhibition of the mTORC pathway in the antiphospholipid syndrome. N Engl J Med 2014;371(4):303-12.

74 Gracia-Tello B, Isenberg D. Kidney disease in primary anti-phospholipid antibody syndrome. Rheumatology (Oxford) 2017;56(7):1069-80.

75 Gerhardsson J, Sundelin B, Zickert A, Padyukov L, Svenungsson E, Gunnarsson I. Histological antiphospholipid-associated nephropathy versus lupus nephritis in patients with systemic lupus erythematosus: an observational cross-sectional study with longitudinal follow-up. Arthritis Res Ther 2015;17:109.

76 Tyden H, Lood C, Gullstrand B, et al. Endothelial dysfunction is associated with activation of the type I interferon system and platelets in patients with systemic lupus erythematosus. RMD open 2017;3(2):e000508.

77 Grenn RC, Yalavarthi S, Gandhi AA, et al. Endothelial progenitor dysfunction associates with a type I interferon signature in primary antiphospholipid syndrome. Ann Rheum Dis 2017;76(2):450-7.

78 Semple JW, Italiano JE, Jr., Freedman J. Platelets and the immune continuum. Nature reviews. Immunology 2011;11(4):264-74.

79 Mantovani A, Cassatella MA, Costantini C, Jaillon S. Neutrophils in the activation and regulation of innate and adaptive immunity. Nature reviews. Immunology 2011;11(8):519-31.

80 Scherlinger M, Sisirak V, Richez C, Lazaro E, Duffau P, Blanco P. New Insights on Platelets and PlateletDerived Microparticles in Systemic Lupus Erythematosus. Current rheumatology reports 2017;19(8):48. 
81 Pereira J, Alfaro G, Goycoolea M, et al. Circulating platelet-derived microparticles in systemic lupus erythematosus. Association with increased thrombin generation and procoagulant state. Thromb Haemost 2006;95(1):94-9.

82 Guiducci S, Distler JH, Jungel A, et al. The relationship between plasma microparticles and disease manifestations in patients with systemic sclerosis. Arthritis and rheumatism 2008;58(9):2845-53.

83 McCarthy EM, Moreno-Martinez D, Wilkinson FL, et al. Microparticle subpopulations are potential markers of disease progression and vascular dysfunction across a spectrum of connective tissue disease. BBA clinical 2017;7:16-22.

84 Wang W, Liu J, Yang B, et al. Modulation of platelet-derived microparticles to adhesion and motility of human rheumatoid arthritis fibroblast-like synoviocytes. PloS one 2017;12(7):e0181003.

85 Nurden AT. Platelets, inflammation and tissue regeneration. Thrombosis and haemostasis 2011;105 Suppl 1:S13-33.

86 Joseph JE, Harrison P, Mackie IJ, Isenberg DA, Machin SJ. Increased circulating platelet-leucocyte complexes and platelet activation in patients with antiphospholipid syndrome, systemic lupus erythematosus and rheumatoid arthritis. Br J Haematol 2001;115(2):451-9.

87 Maugeri N, Campana L, Gavina M, et al. Activated platelets present high mobility group box 1 to neutrophils, inducing autophagy and promoting the extrusion of neutrophil extracellular traps. Journal of Thrombosis and Haemostasis 2014;12(12):2074-88.

88 Totani L, Evangelista V. Platelet-leukocyte interactions in cardiovascular disease and beyond. Arteriosclerosis, thrombosis, and vascular biology 2010;30(12):2357-61.

89 Kambas K, Chrysanthopoulou A, Vassilopoulos D, et al. Tissue factor expression in neutrophil extracellular traps and neutrophil derived microparticles in antineutrophil cytoplasmic antibody associated vasculitis may promote thromboinflammation and the thrombophilic state associated with the disease. Annals of the rheumatic diseases 2014;73(10):1854-63.

90 Engelmann B, Massberg S. Thrombosis as an intravascular effector of innate immunity. Nature reviews. Immunology 2013;13(1):34-45.

91 Jimenez-Alcazar M, Rangaswamy C, Panda R, et al. Host DNases prevent vascular occlusion by neutrophil extracellular traps. Science 2017;358(6367):1202-6.

92 Radic M, Herrmann M, van der Vlag J, Rekvig OP. Regulatory and pathogenetic mechanisms of autoantibodies in SLE. Autoimmunity 2011;44(5):349-56.

93 Villanueva E, Yalavarthi S, Berthier CC, et al. Netting neutrophils induce endothelial damage, infiltrate tissues, and expose immunostimulatory molecules in systemic lupus erythematosus. J Immunol 2011;187(1):538-52.

94 Garcia-Romo GS, Caielli S, Vega B, et al. Netting neutrophils are major inducers of type I IFN production in pediatric systemic lupus erythematosus. Sci Transl Med 2011;3(73):73ra20.

95 Kahlenberg JM, Thacker SG, Berthier CC, Cohen CD, Kretzler M, Kaplan MJ. Inflammasome activation of IL-18 results in endothelial progenitor cell dysfunction in systemic lupus erythematosus. J Immunol 2011;187(11):6143-56.

96 Menegazzo L, Ciciliot S, Poncina N, et al. NETosis is induced by high glucose and associated with type 2 diabetes. Acta diabetologica 2015;52(3):497-503.

97 Kessenbrock K, Krumbholz M, Schonermarck U, et al. Netting neutrophils in autoimmune small-vessel vasculitis. Nature medicine 2009;15(6):623-5.

98 Khandpur R, Carmona-Rivera C, Vivekanandan-Giri A, et al. NETs are a source of citrullinated autoantigens and stimulate inflammatory responses in rheumatoid arthritis. Sci Transl Med 2013;5(178):178ra40.

99 Yalavarthi S, Gould TJ, Rao AN, et al. Release of neutrophil extracellular traps by neutrophils stimulated with antiphospholipid antibodies: a newly identified mechanism of thrombosis in the antiphospholipid syndrome. Arthritis \& rheumatology 2015;67(11):2990-3003.

100 Manfredi AA, Rovere-Querini P, D'Angelo A, Maugeri N. Low molecular weight heparins prevent the induction of autophagy of activated neutrophils and the formation of neutrophil extracellular traps. Pharmacol Res 2017;123:146-56. 
101 Stakos DA, Kambas K, Konstantinidis T, et al. Expression of functional tissue factor by neutrophil extracellular traps in culprit artery of acute myocardial infarction. European heart journal 2015;36(22):140514.

102 Dieker J, Tel J, Pieterse E, et al. Circulating Apoptotic Microparticles in Systemic Lupus Erythematosus Patients Drive the Activation of Dendritic Cell Subsets and Prime Neutrophils for NETosis. Arthritis \& rheumatology 2016;68(2):462-72.

103 Mehta BM, Kiani AN, Chen C, Jani J, Kickler TS, Petri M. Endogenous thrombin potential in the assessment of hypercoagulability in systemic lupus erythematosus. Am J Hematol 2010;85(1):83-5.

104 Kern A, Barabas E, Balog A, Burcsar S, Kiszelak M, Vasarhelyi B. Characterization of the thrombin generation profile in systemic lupus erythematosus. Physiology international 2017;104(1):35-41.

105 Kiraz S, Ertenli I, Benekli M, et al. Clinical significance of hemostatic markers and thrombomodulin in systemic lupus erythematosus: evidence for a prothrombotic state. Lupus 1999;8(9):737-41.

106 Palatinus A, Adams M. Thrombosis in systemic lupus erythematosus. Semin Thromb Hemost 2009;35(7):621-9.

107 Roldan V, Marco P, Fernandez C, Pascual E. Levels of tissue factor pathway inhibitor in lupus patients correlate with lupus activity and endothelial damage markers. Haematologica 2002;87(11):1231-2.

108 Liestol S, Sandset PM, Jacobsen EM, Mowinckel MC, Wisloff F. Decreased anticoagulant response to tissue factor pathway inhibitor type 1 in plasmas from patients with lupus anticoagulants. $\mathrm{Br} \mathrm{J}$ Haematol 2007;136(1):131-7.

109 Ertenli I, Kiraz S, Celik IC, et al. Changes in the concentration and distribution of tissue factor pathway inhibitor in Behcet's disease and systemic lupus erythematosus: effect on the prethrombotic state. Ann Rheum Dis 2001;60(12):1149-51.

110 Bouwens EA, Stavenuiter F, Mosnier LO. Mechanisms of anticoagulant and cytoprotective actions of the protein C pathway. J Thromb Haemost 2013;11 Suppl 1:242-53.

111 Bae JS, Yang L, Rezaie AR. Receptors of the protein C activation and activated protein C signaling pathways are colocalized in lipid rafts of endothelial cells. Proc Natl Acad Sci U S A 2007;104(8):2867-72.

112 Healy LD, Puy C, Fernandez JA, et al. Activated protein C inhibits neutrophil extracellular trap formation in vitro and activation in vivo. J Biol Chem 2017;292(21):8616-29.

113 Lance MD. A general review of major global coagulation assays: thrombelastography, thrombin generation test and clot waveform analysis. Thrombosis journal 2015;13:1.

114 Hemker HC, Al Dieri R, De Smedt E, Beguin S. Thrombin generation, a function test of the haemostatic-thrombotic system. Thromb Haemost 2006;96(5):553-61.

115 Eichinger S, Hron G, Kollars M, Kyrle PA. Prediction of recurrent venous thromboembolism by endogenous thrombin potential and D-dimer. Clin Chem 2008;54(12):2042-8.

116 Asero R, Tedeschi A, Riboldi P, Cugno M. Plasma of patients with chronic urticaria shows signs of thrombin generation, and its intradermal injection causes wheal-and-flare reactions much more frequently than autologous serum. The Journal of allergy and clinical immunology 2006;117(5):1113-7.

117 Baranes D, Matzner J, Razin E. Thrombin-induced calcium-independent degranulation of human neutrophils. Inflammation 1986;10(4):455-61.

118 Kahn ML, Nakanishi-Matsui M, Shapiro MJ, Ishihara H, Coughlin SR. Protease-activated receptors 1 and 4 mediate activation of human platelets by thrombin. The Journal of clinical investigation 1999;103(6):879-87.

119 Huber-Lang M, Sarma JV, Zetoune FS, et al. Generation of C5a in the absence of C3: a new complement activation pathway. Nature medicine 2006;12(6):682-7.

120 Fischetti F, Tedesco F. Cross-talk between the complement system and endothelial cells in physiologic conditions and in vascular diseases. Autoimmunity 2006;39(5):417-28.

121 Arachchillage DR, Mackie IJ, Efthymiou M, et al. Rivaroxaban limits complement activation compared with warfarin in antiphospholipid syndrome patients with venous thromboembolism. J Thromb Haemost 2016;14(11):2177-86.

122 Ekdahl KN, Teramura Y, Hamad OA, et al. Dangerous liaisons: complement, coagulation, and kallikrein/kinin cross-talk act as a linchpin in the events leading to thromboinflammation. Immunological reviews 2016;274(1):245-69. 
123 Back J, Lood C, Bengtsson AA, Ekdahl KN, Nilsson B. Contact activation products are new potential biomarkers to evaluate the risk of thrombotic events in systemic lupus erythematosus. Arthritis Res Ther 2013;15(6):R206.

124 D'Agostino RB, Sr., Vasan RS, Pencina MJ, et al. General cardiovascular risk profile for use in primary care: the Framingham Heart Study. Circulation 2008;117(6):743-53.

125 Bessant R, Duncan R, Ambler G, et al. Prevalence of conventional and lupus-specific risk factors for cardiovascular disease in patients with systemic lupus erythematosus: A case-control study. Arthritis Rheum 2006;55(6):892-9.

126 Sciascia S, Sanna G, Murru V, Roccatello D, Khamashta MA, Bertolaccini ML. GAPSS: the Global AntiPhospholipid Syndrome Score. Rheumatology (Oxford) 2013;52(8):1397-403.

127 Petri M, Magder LS. Systemic Lupus Erythematosus Cardiovascular Risk Equation. Paper presented at ACR Annual Scientific Meeting; 2009.

128 Boulos D, Koelmeyer RL, Morand EF, Hoi AY. Cardiovascular risk profiles in a lupus cohort: what do different calculators tell us? Lupus science \& medicine 2017;4(1):e000212.

129 Urowitz MB, Ibanez D, Su J, Gladman DD. Modified Framingham Risk Factor Score for Systemic Lupus Erythematosus. J Rheumatol 2016;43(5):875-9.

130 Bazzan M, Vaccarino A, Marletto F. Systemic lupus erythematosus and thrombosis. Thrombosis journal 2015;13:16.

131 Kaiser R, Barton JL, Chang $\mathrm{M}$, et al. Factor $\mathrm{V}$ Leiden and thrombosis in patients with systemic lupus erythematosus: a meta-analysis. Genes Immun 2009;10(5):495-502.

132 Somers E, Magder LS, Petri M. Antiphospholipid antibodies and incidence of venous thrombosis in a cohort of patients with systemic lupus erythematosus. J Rheumatol 2002;29(12):2531-6.

133 Ruiz-Irastorza G, Cuadrado MJ, Ruiz-Arruza I, et al. Evidence-based recommendations for the prevention and long-term management of thrombosis in antiphospholipid antibody-positive patients: report of a task force at the 13th International Congress on antiphospholipid antibodies. Lupus 2011;20(2):206-18.

134 Erkan D, Aguiar CL, Andrade D, et al. 14th International Congress on Antiphospholipid Antibodies: task force report on antiphospholipid syndrome treatment trends. Autoimmun Rev 2014;13(6):685-96.

135 Keeling D, Mackie I, Moore GW, Greer IA, Greaves M, British Committee for Standards in H. Guidelines on the investigation and management of antiphospholipid syndrome. $\mathrm{Br} J$ Haematol 2012;157(1):47-58.

136 Cohen $\mathrm{H}$, Hunt BJ, Efthymiou M, et al. Rivaroxaban versus warfarin to treat patients with thrombotic antiphospholipid syndrome, with or without systemic lupus erythematosus (RAPS): a randomised, controlled, open-label, phase 2/3, non-inferiority trial. The Lancet. Haematology 2016;3(9):e426-36.

137 Espinosa G, Cervera R. Current treatment of antiphospholipid syndrome: lights and shadows. Nat Rev Rheumatol 2015;11(10):586-96.

138 Erkan D, Vega J, Ramon G, Kozora E, Lockshin MD. A pilot open-label phase II trial of rituximab for non-criteria manifestations of antiphospholipid syndrome. Arthritis Rheum 2013;65(2):464-71.

139 Arnaud L, Mathian A, Devilliers $\mathrm{H}$, et al. Patient-level analysis of five international cohorts further confirms the efficacy of aspirin for the primary prevention of thrombosis in patients with antiphospholipid antibodies. Autoimmun Rev 2015;14(3):192-200.

140 Babary $\mathrm{H}$, Liu X, Ayatollahi $\mathrm{Y}$, et al. Favorable effects of hydroxychloroquine on serum low density lipid in patients with systemic lupus erythematosus: A systematic review and meta-analysis. International journal of rheumatic diseases 2018;21(1):84-92.

141 Fasano S, Pierro L, Pantano I, ludici M, Valentini G. Longterm Hydroxychloroquine Therapy and Lowdose Aspirin May Have an Additive Effectiveness in the Primary Prevention of Cardiovascular Events in Patients with Systemic Lupus Erythematosus. J Rheumatol 2017;44(7):1032-8.

142 Hsu CY, Lin YS, Su YJ, et al. Effect of long-term hydroxychloroquine on vascular events in patients with systemic lupus erythematosus: a database prospective cohort study. Rheumatology (Oxford) 2017;56(12):2212-21.

143 Ruiz-Irastorza G, Egurbide MV, Pijoan JI, et al. Effect of antimalarials on thrombosis and survival in patients with systemic lupus erythematosus. Lupus 2006;15(9):577-83. 
144 Tu H, Li Q, Xiang S, et al. Dual effects of statins therapy in systemic lupus erythematosus and SLErelated atherosclerosis: the potential role for regulatory T cells. Atherosclerosis 2012;222(1):29-33.

$145 \mathrm{Yu} \mathrm{HH}$, Chen PC, Yang YH, et al. Statin reduces mortality and morbidity in systemic lupus erythematosus patients with hyperlipidemia: A nationwide population-based cohort study. Atherosclerosis 2015;243(1):11-8.

146 Willis R, Seif AM, McGwin G, Jr., et al. Effects of statins on proinflammatory/prothrombotic biomarkers and on disease activity scores in SLE patients: data from LUMINA (LXXVI), a multi-ethnic US cohort. Clin Exp Rheumatol 2014;32(2):162-7.

147 Ruiz-Limon P, Barbarroja N, Perez-Sanchez C, et al. Atherosclerosis and cardiovascular disease in systemic lupus erythematosus: effects of in vivo statin treatment. Ann Rheum Dis 2015;74(7):1450-8.

148 van den Hoogen LL, Fritsch-Stork RD, Versnel MA, Derksen RH, van Roon JA, Radstake TR. Monocyte type I interferon signature in antiphospholipid syndrome is related to proinflammatory monocyte subsets, hydroxychloroquine and statin use. Ann Rheum Dis 2016;75(12):e81.

149 Wang H, Li T, Chen S, Gu Y, Ye S. Neutrophil Extracellular Trap Mitochondrial DNA and Its Autoantibody in Systemic Lupus Erythematosus and a Proof-of-Concept Trial of Metformin. Arthritis \& rheumatology 2015;67(12):3190-200.

150 Sahebkar A, Rathouska J, Derosa G, Maffioli P, Nachtigal P. Statin impact on disease activity and Creactive protein concentrations in systemic lupus erythematosus patients: A systematic review and metaanalysis of controlled trials. Autoimmun Rev 2016;15(4):344-53. 
FIGURE 1: main pathogenic determinants of thromboembolic risk in SLE

Accelerated atherosclerosis, antiphospolipid antibodies (aPL), abnormal interactions between platelets, leukocytes and the endothelium and aberrant activation of the coagulation cascade account for increased thromboembolic risk in patients with SLE.

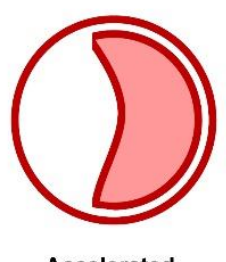

Accelerated atherosclerosis

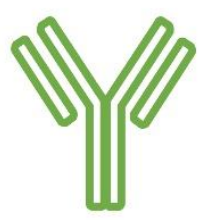

Antiphospholipid antibodies

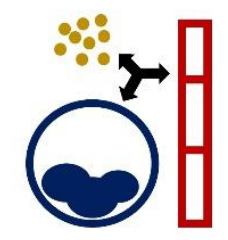

Altered platelet leukocyte - endothelial network

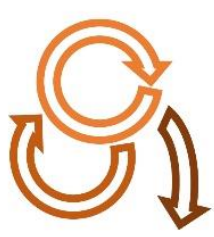

Dysfunctional coagulation cascade 
FIGURE 2: factors involved in accelerated atherosclerosis in SLE

Deranged immune responses promote endothelial activation and facilitate the extravasation of leukocytes. Monocytes respond to the accumulation of oxidised lipid products within the vessel walls and disrupt the physiological architecture of their inner layers. This process is potentially favoured by unbalanced T cell activation as well as by an interferon-enriched environment and can occur over short periods of time during disease flares. Interferon responses also account for impaired endothelial turnover and endothelial dysfunction in patients with SLE. Conventional cardiovascular risk factors further promote the development of atherosclerosis in SLE. Antiphospholipid antibodies (aPL) also promote chronic atherosclerotic lesions besides prompting thrombosis.

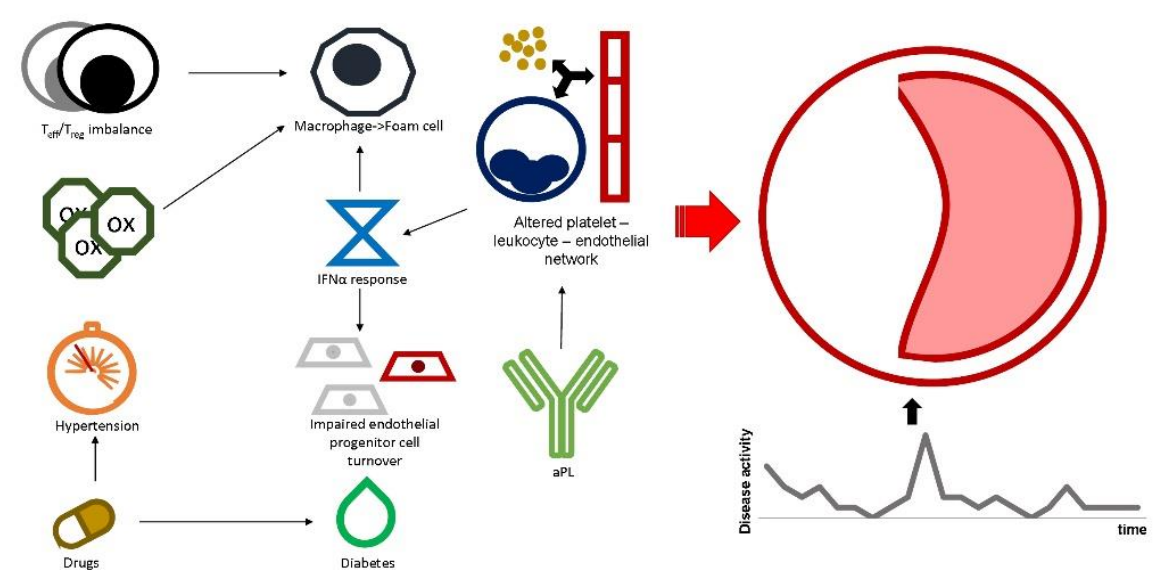




\section{FIGURE 3: pathogenic effects of antiphospholipid antibodies}

Antiphospholipid antibodies (aPL) jeopardise physiological haemostasis through several mechanisms, which include facilitation of the coagulation cascade, activation of the endothelium and promotion of long-term vessel remodelling, complement activation, recruitment of inflammatory cells and inhibition of the scavenger, antinflammatory or antithrombotic properties of their antigenic targets. Most aPL recognise the linearised form of beta 2 glycoprotein I ( $\beta 2 \mathrm{GPI}$ ) as their ligand and affect cellular activation through Toll-like receptor (TLR)1,2,4 and 6, annexin (Anx) A2, apolipoprotein E receptor 2 (ApoER2) and other yet unknown receptors. Nonetheless, other antigens such as phosphatidylserine/prothrombin complexes or annexin A5 (AnxA5) might be relevant target for aPL.

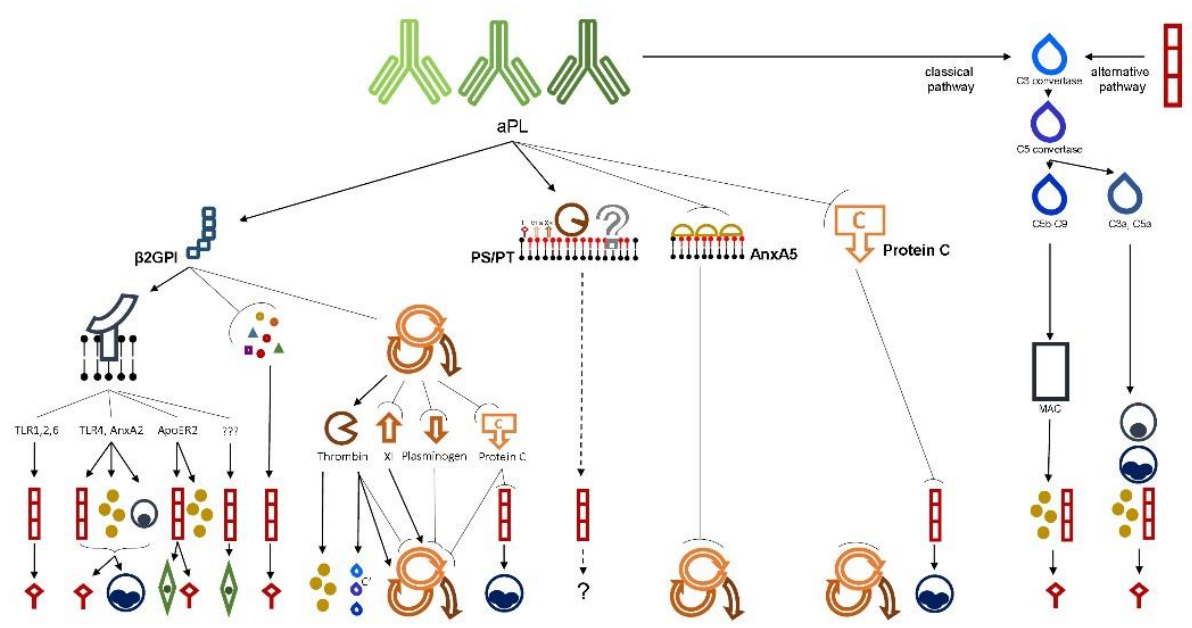




\section{FIGURE 4: platelet-leukocyte-endothelial interactions in SLE}

Upon activation, neutrophils are able to promote thrombosis by expressing tissue factor and by generating neutrophil extracellular traps (NETs). The activation of neutrophils can be induced by several stimuli, including interactions with activated platelets by cell-cell contact or by microparticles (yellow dots). Interferon alpha can also promote NETosis and affect endothelial turnover. The endothelium also plays a crucial role in triggering coagulation through tissue factor and by providing leukocytes with the access to tissues. Besides exerting a role in the control of local inflammation and haemostasis, the endothelium can also extend its functions systemically, through microparticles (red dots).

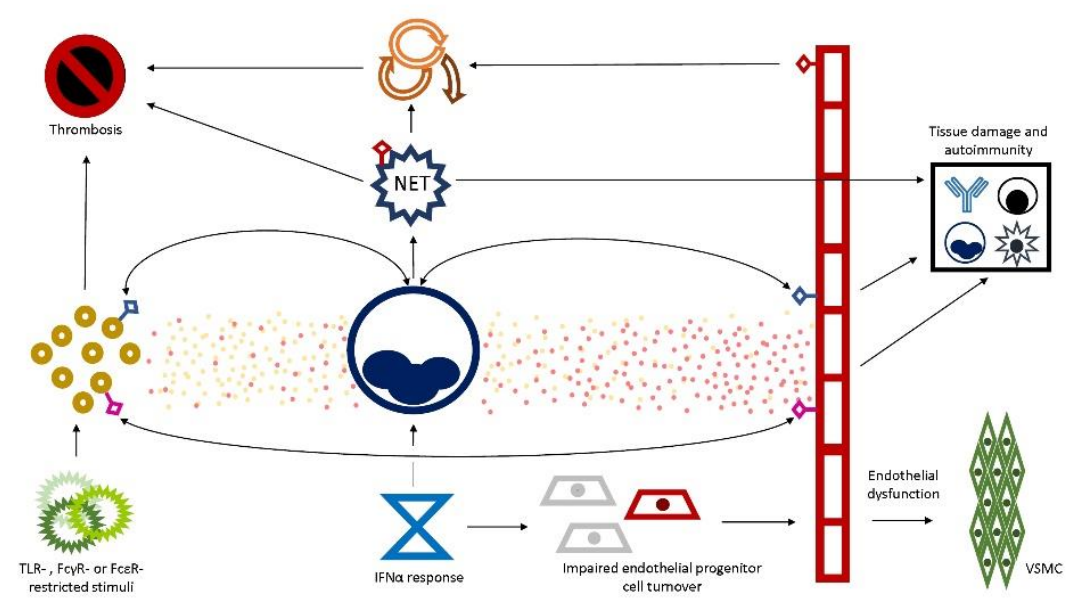

\section{FIGURE 5: the coagulation cascade in SLE}

An active interplay links the coagulation cascade with inflammation in SLE. Inflammation induces the expression of TF on the endothelium and on circulating platelets, leukocytes, platelet-derived and endothelial-derived microparticles (yellow and red dots respectively). NETting neutrophils constitute additional sources of TF, activate factor XII and neutralise TFPI. TF, in combination with phospholipids (provided by activated cells), activated factor VII and calcium, constitutes the main trigger of the coagulation cascade in vivo. Thrombin can interact with multiple cellular and humoral immune mediators, including complement. SLE can impair the regulation of the coagulation cascade at different levels including TFPI and protein C. 


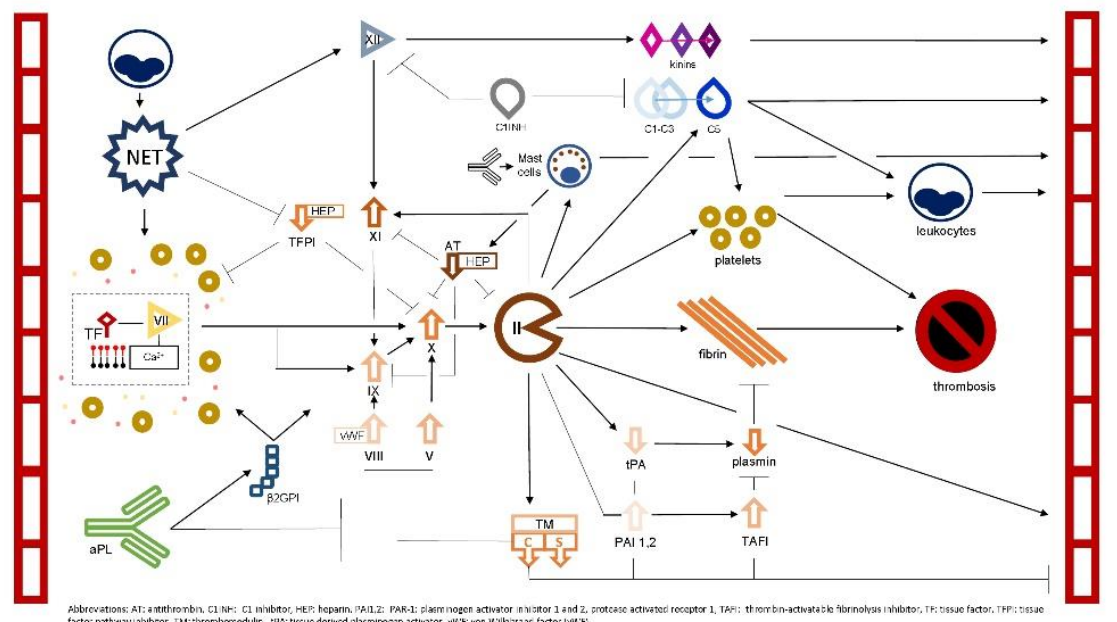

